\title{
R-GVD Regimen
}

National Cancer Institute

\section{Source}

National Cancer Institute. R-GVD Regimen. NCI Thesaurus. Code C140733.

A regimen consisting of rituximab, gemcitabine, vinorelbine and pegylated liposomal doxorubicin that can be used in the treatment of Hodgkin lymphoma $(\mathrm{HL})$ and diffuse large B-cell lymphoma (DLBCL). 